International Journal of Dentistry and Oral Science (1JDOS)

ISSN: 2377-8075

\title{
Antimicrobial Effect of Different Root Canal Medicaments on Enterococcus Faecalis: in vitro Comparative Study
}

Asmaa MM¹, Alaa A. El-Agamy², Ibtesam K.Afifi, ${ }^{13^{*}}$

Research Article

${ }^{1}$ Department of Medical Microbiology \& Immunology, Faculty of Medicine, Tanta University, Egypt.

${ }^{2}$ Dental Surgery Specialist, University Clinic; Taif University, KSA.

${ }^{3}$ Department of Basic \& Clinical Oral Sciences, Faculty of Dentistry, Umm Al-Qura University, KSA

\section{Abstract}

Introduction: Enterococcus faecalis (E. faecalis) is a microorganism commonly detected in persistent endodontic infections. Eradication of this organism from an infected root canal remains a significant clinical challenge for modern endodontic treatment. So, this in vitro study was conducted to compare antimicrobial effect of some root canal medicaments on $E$. faecalis.

Materials/Methods: A total of 50 E. faecalis strains (49 strains were selected randomly from positive cultures together with a standard E. faecalis strain ATCC 29212) were used in the study. Inoculum for each bacterial strain was prepared in a turbidity of 0.5 on McFarland scale. The prepared discs of the three intracanal medicaments; chlorhexidine, diapex and diclofenac; together with readymade discs of amoxicillin and doxycycline were distributed on blood agar and Mueller-Hinton agar plates inoculated with an E. faecalis suspension previously prepared. Antimicrobial activity was assessed by measuring the diameters of the zones of growth inhibition surround the discs after incubation at $37^{\circ} \mathrm{C}$ for 24 hours and then after 48 hours.

Results: All strains (100\%) were sensitive to chlorhexidine even though strains that showed resistance to one or both of antibiotic used (amoxicillin, doxycycline). On the other hand, all strains (100\%) were resistant to diapex and diclofenac even standard strain. Sixty eight percent of the tested strains were sensitive to doxycyline and $44 \%$ of them were sensitive to amoxicillin.

Conclusion: Under the conditions of this study, chlorhexidine is very effective against E. faecalis and can be considered as the most powerful root canal medicament compared to other intracanal medicaments tested. Controversially, no zones of inhibition were detected around diapex and diclofenac.

Keywords: Enterococcus Faecalis; Root Canal Medicaments; Antibacterial Effect; Chlorhexidine; Diapex; Diclofenac; Amoxicillin; Doxycycline.

\section{*Corresponding Author:}

Ibtesam K. Afifi,

Faculty of Medicine, Department of Medical Microbiology \& Immunology, Tanta University, Tanta, Egypt.

Tel: 00966541455073

E-mail: dr.ibtesamafifi@yahoo.com

Received: November 18, 2014

Accepted: December 02, 2014

Published: December 11, 2014

Citation: Asmaa MM, Alaa A. El-Agamy, AIbtesam K.Afifi (2014) Antimicrobial Effect of Different Root Canal Medicaments on Enterococcus Faecalis: In vitro Comparative Study. Int J Dentistry Oral Sci. 1(2), 15-20. doi: http://dx.doi.org/10.19070/2377-8075-140004

Copyright: Afifi IK ${ }^{\circ}$ 2014. This is an open-access article distributed under the terms of the Creative Commons Attribution License, which permits unrestricted use, distribution and reproduction in any medium, provided the original author and source are credited.

\section{Introduction}

Successful endodontic treatment aims at elimination of microbial infection in the root canal system and prevents regrowth of residual microorganisms. If sufficient instrumentation and irrigation can eliminate all microorganisms in the root canal system at the first appointment, most treatments could be finished in one visit. However, complete elimination of bacteria is not always obtained in clinical practice due to the anatomical complexities of root canals and limitations of medicaments. [1,2]

The use of root canal filling materials with antibacterial activity can be considered beneficial to reduce the remaining microorganisms in the root canal system, and prevent recurrent infection. [3]

E. faecalis is the most commonly isolated bacteria from root canals of teeth with persistent periapical periodontitis and it is frequently isolated from both secondary and persistent root canal infections. [4,5]

Moreover, this microorganism has shown resistance to several irrigating solutions and medications used in endodontics. [6]

A large number of substances have been tested against E. faecalis, with conflicting results. [6-8] thus, investigations leading to an efficient intracanal medicament capable of eliminating E. faecalis from root canals and dentin tubules are desirable.

Since its introduction in 1920 , calcium hydroxide has been widely used in endodontics. It has been recommended for use as intracanal medicaments and in several other clinical situations. [9] Several works have studied the mixture of other substances to calcium 
hydroxide with the purpose of improving some of its properties. Among these additional substances are vehicles that can speed up or slow down ionic dissociation, substances that aid the filling of pulpal cavity by means of their consistency, substances used as antimicrobial medium and media that enhance radiopacity. [10,11]. Of these mixtures recently used is diapex which is a silicone oilbased calcium hydroxide paste containing 38\% iodoform.

Moreover, chlorhexidine (CHX) can be applied clinically as antimicrobial agent during all phases of the root canal preparation as an intracanal medicament either alone or combined with other substances. [12]

Diclofenac sodium, a non steroidal anti inflammatory drug, has been described as non antibiotic that showed significant protection of the mouth against infection by wide variety of highly virulent organisms at lower doses in comparison to its in vivo analgesic dose. It showed bactericidal effect against both gram positive and gram negative bacteria [13]. Salem-Milani et al., [14] reported that diclofenac had significantly pronounced antibacterial activity against $E$. faecalis.

On the other hand, antibiotics may be applied systemically or locally (irrigants and medicaments) during endodontic treatment. Owing to the potential risk of adverse effects and ineffectiveness of systemic antibiotics in necrotic pulpless teeth and the periradicular tissues, the local application of antibiotics may be a more effective mode for delivery in endodontics. $[15,16]$

Due to their effectiveness, minimal toxicity and relatively low cost, penicillins, including amoxicillin constitute the first choice of antibiotics for odontogenic infections [17]. Furthermore, tetracyclines, including doxycycline have been used to remove the smear layer from instrumented root canal walls, for irrigation of apical root-end cavities during periapical surgical procedures, and as an intracanal medicament [18].

So, the aim of this study was to evaluate the in vitro antimicrobial activity of amoxicillin, doxycycline, chlorhexidine, diapex and diclofenac against various strains of E. faecalis as organism implicated in failed enodontic treatment.

\section{Materials and Methods}

Antibacterial properties of two commonly used root canal fillings medicaments together with diclofenac sodium and two antibiotics were studied on E. faecalis

The medicaments used for the study were as follows:

1. Diapex Plus (Calcium Hydroxide paste with iodoform) (DiaDent, Seoul, Korea) .

2. Chlorohexidine Gluconate solution 2\% (Ultradent Products, South Jordan, Utah, USA).

3. Diclofenac sodium $0.1 \%$ (Ocugesic, Riyadh Pharma, KSA) .

4. Amoxicillin $10 \mu \mathrm{g}$ (OXOID, Basingstoke Hampshire, England).

5. Doxycycline $30 \mu \mathrm{g}$ (OXOID, Basingstoke Hampshire, England).

\section{Intracanal medicaments discs preparation}

Discs of 6 millimetre diameters were prepared with a puncher from Whatman paper No.1 and sterilized by hot air oven.
Diapex paste (calcium hydroxide with iodoform) was prepared in $0.22 \mathrm{gm} / \mathrm{ml}$ by dissolving it in ethanol $(99.9 \%)$ and by heating until it completely dissolved. [19]

These discs were then saturated with $50 \mu$ l of each medicament (the prepared solution of diapex and liquid intracanal medication agents, chlorhexidine and diclofenac sodium) using automatic pipette with sterile tips then left to dry.

\section{E. faecalis suspension preparation}

A total of 50 E. faecalis strains (49 strains were selected randomly from positive cultures together with a standard E. faecalis strain ATCC 29212) were used in the study.

E. faecalis strains grown from different clinical samples were identified using colonial morphology, Gram staining characteristics, negative catalase test, latex streptococcus group D (slidex streptoplus, BioMerieux SA- France) and run on microscan (Siemens Microscan WalkAway system, Germany) for full identification.

Standard strain of E. faecalis (ATCC 29212), obtained from the American Type Culture Collection TM (ATCC, Rockville, MD, EUA), were taken from frozen stock culture and inoculated into Trypticase Soy Broth (TSB, Difco Lab, Detroit, MI, USA), grown overnight at $37^{\circ} \mathrm{C}$, and streaked onto blood agar plates. The cultures were then checked for purity by Gram stain and colony morphology, and after that it was fully identified as in the test strains.

Inoculum for each bacterial strain was prepared by picking up four to five colonies with the help of sterilized loop and dissolving them into test tube containing $5 \mathrm{ml}$ of $0.85 \%$ saline solution to produce a turbidity of 0.5 on $\mathrm{McF}$ arland scale $\left(1.5 \mathrm{X} 10^{8} \mathrm{CFU} /\right.$ $\mathrm{ml})$.

\section{Intracanal medicaments sensitivity testing}

Sterile cotton swab rolled in the suspension to streak the plate surface of blood agar and Muller - Hilton - Agar plates (MHA plate) (Oxoid, Cambridge, UK) for E. faecalis. The prepared discs of the three intracanal medicaments together with readymade discs of amoxicillin and doxycycline (OXOID, Basingstoke Hampshire, England) were then aseptically transferred and distributed on blood agar and Mueller-Hinton agar plates inoculated with an E. faecalis suspension.

Inoculated plates were then incubated at $37^{\circ} \mathrm{C}$ under the appropriate gaseous conditions for 48 hours.

Antimicrobial activity was assessed by measuring the diameter (in millimeters) of the zone of growth inhibition surround the discs, at the nearest distance between two points at the outer limit of the inhibition zone formed around the discs using a caliper after incubation for 24 then 48 hrs.

\section{Statistical analysis}

Data collected and analyzed using SPSS package system.V.11. Mean and standard deviation were calculated. Comparison between the antibacterial efficacies of medicaments on E. faecalis was analyzed.

\section{Reliability and validity of the test}


The measurement for each zone of inhibition was repeated independently in triplicate to minimize the errors and ensure reproducibility. The reliability of the three tests was compared statistically weighted Kappa. The Kappa statistics was 0.98.

\section{Results}

Standard E. faecalis ATCC 29212 strain used as control strain in the present study showed sensitivity to chlorhexidine, amoxicillin $10 \mu \mathrm{g}$ and doxycycline $30 \mu \mathrm{g}$, while it was resistant to diapex, and diclofenac (tables 1\&2) and zones of inhibition were closely simillar after 24 and 48 hours. Sensitivity to antibiotics amoxicillin $10 \mu \mathrm{g}$ and doxycycline $30 \mu \mathrm{g}$ was calculated according to CLSI [20] guidelines. It shows that doxycycline is considered sensitive when diameters zone of inhibition is $\geq 16 \mathrm{~mm}$, Intermediate sensitive when it is $13-15 \mathrm{~mm}$ and resistant when it is $\leq 12 \mathrm{~mm}$. Regarding amoxicillin $10 \mu \mathrm{g}$, CLSI 2014 guidelines show that it is considered sensitive when the diameters zone of inhibition is $\geq 17 \mathrm{~mm}$ and resistant when it is $\leq 16 \mathrm{~mm}$. Chlorhexidine was considered sensitive when the zone of inhibition was more than $12.5 \mathrm{~mm}$ according to Vianna and Gomes [21]. On the other hand, as there is no reference data for sensitivity of diapex, diclofenac; standard strain was used as a reference for comparison to the diameter of inhibition zone.

Tables 1 and 2 show the mean and standard deviation of microbial zones of inhibition by tested antimicrobial agents against both standard and clinically isolated E. faecalis strains on both Muller Hinton and blood agar and also after 24 and 48 hours incubation.

On measuring zones of E. faecalis growth inhibition by different tested antimicrobials, all strains $(100 \%)$ were sensitive to chlorhexidine even though strains that showed resistance to one or both of antibiotic used (amoxicillin, doxycycline). On the other hand, all strains $(100 \%)$ were resistant to diapex and diclofenac even standard strain (table 3). Thus, chlorhexidine is the most effective intracanal medicament against E. faecalis in this study fol- lowed by doxycycline then amoxicillin. On the other hand, diapex, and diclofenac were not effective antimicrobial agents against $E$. faecalis.

In comparison to standard strain, non significant differences was found between zones of inhibition of chlorhexidine and doxycycline, after 24 and 48 hours incubation on both used media. On the other hand, diclofenac, diapex and amoxicillin inhibition zones showed significant differences (tables $4 \& 5$ ).

All tested strains were cultured on two media (Mullar Hinton agar and blood agar plates) for different periods ( $24 \mathrm{hs} \& 48 \mathrm{hs}$ ) for comparison and results showed non significant difference between them.

\section{Discussion}

E. faecalis is a persistent pathogen that is believed to play a major role in the etiology of persistent periradicular lesions after root canal treatment although it makes up only a small proportion of the flora in untreated canals. [22]

Therefore, E. faecalis is often used as a model organism in the testing of irrigants and medicaments to treat apical periodontitis [23]. So, this study was conducted to evaluate the in vitro antimicrobial activity of different antimicrobials used as intra canal medicaments against various species of E. faecalis. American Type Culture Collection E. faecalis strain (ATCC) no. 29212 widely used as a reference strain in antimicrobial susceptibility studies, was selected for comparison of the growth inhibition zones with clinically isolated strains.

The results of the current study showed that chlorhexidine is the most effective intracanal medicament against E. faecalis. This result is in agreement with several authors who found that the medicaments containing chlorhexidine were highly effective against E. faecalis $[21,24-27]$.

Table 1. Mean \pm SD of growth inhibitory zones of clinically isolated strains on Muller Hinton agar after 24 and 48 hours incubation in comparison of inhibitory zone of standard strain

\begin{tabular}{|c|c|c|c|}
\hline \multirow{2}{*}{$\begin{array}{c}\text { Root canal } \\
\text { medicaments groups }\end{array}$} & Standard E. faecalis & \multicolumn{2}{|c|}{ Clinically isolated E. faecalis strains } \\
\cline { 3 - 4 } & ATCC 29212 & After 24 hours & After 48 hours \\
\hline Chlorhexidine & 17.00 & $16.94 \pm 1.984$ & $16.98 \pm 1.995$ \\
\hline Diclofenac & 8.00 & $8.28 \pm .904$ & $8.28 \pm .904$ \\
\hline Diapex & 8.00 & $8.64 \pm .749$ & $8.64 \pm .749$ \\
\hline Amoxicillin & 17.00 & $13.46 \pm 3.512$ & $13.48 \pm 3.710$ \\
\hline Doxycycline & 17.00 & $17.62 \pm 5.710$ & $17.5 \pm 6.175$ \\
\hline
\end{tabular}

Table 2. Mean \pm SD of growth inhibitory zones of clinically isolated strains on Blood agar after 24 and 48 hours incubation in comparison of inhibitory zone of standard strain

\begin{tabular}{|c|c|c|c|}
\hline Root canal & Standard E. faecalis & \multicolumn{2}{|c|}{ Clinically isolated E. faecalis strains } \\
\cline { 3 - 4 } medicaments groups & ATCC 29212 & After 24 hours & After 48 hours \\
\hline Chlorhexidine & 15.00 & $15.440 \pm 3.5637$ & $15.440 \pm 3.5637$ \\
\hline Diclofenac & 8.00 & $8.3000 \pm .9091$ & $8.300 \pm .9091$ \\
\hline Diapex & 8.00 & $8.2000 \pm .63888$ & $8.200 \pm .63888$ \\
\hline Amoxicillin & 18.00 & $14.7200 \pm 3.0036$ & $14.7200 \pm 3.00367$ \\
\hline Doxycycline & 16.00 & $14.980 \pm 6.55429$ & $14.9800 \pm 6.55429$ \\
\hline
\end{tabular}


Table 3. Number and percentage of sensitive strains to the tested antimicrobial agents

\begin{tabular}{|c|c|c|}
\hline $\begin{array}{c}\text { Root canal } \\
\text { medicaments groups }\end{array}$ & $\begin{array}{c}\text { No. of sensitive } \\
\text { strains }\end{array}$ & $\begin{array}{c}\text { Percentage } \% \text { of sensitive } \\
\text { strains }\end{array}$ \\
\hline Chlorhexidine & 50 & $100 \%$ \\
\hline Diclofenac & 0 & $0 \%$ \\
\hline Diapex & 0 & $0 \%$ \\
\hline Amoxicillin & 22 & $44 \%$ \\
\hline Doxycycline & 34 & $68 \%$ \\
\hline
\end{tabular}

Table 4. Comparison of antimicrobial effects of root canal medicaments groups on clinically isolated E. faecalis strains in relation to standard E. faecalis ATCC 29212 on Muller Hinton agar

\begin{tabular}{|c|c|c|c|c|}
\hline \multirow{2}{*}{$\begin{array}{c}\text { Root canal } \\
\text { medicaments groups }\end{array}$} & \multicolumn{2}{|c|}{$\begin{array}{c}\text { Antimicrobial effects } \\
\text { after 24 hours incubation }\end{array}$} & \multicolumn{2}{c|}{$\begin{array}{c}\text { Antimicrobial effects after 48 } \\
\text { hours incubation }\end{array}$} \\
\cline { 2 - 5 } & $\mathrm{t}$ value & P value & $\mathrm{t}$ value & P value \\
\hline Chlorhexidine & 0.214 & 0.832 & 0.071 & 0.944 \\
\hline Diclofenac & 2.189 & $0.033^{*}$ & 2.189 & $0.033^{*}$ \\
\hline Diapex & 6.039 & $0.000^{*}$ & 6.039 & $0.000^{*}$ \\
\hline Amoxicillin & 7.127 & $0.000^{*}$ & 6.709 & $0.000^{*}$ \\
\hline Doxycycline & 0.768 & 0.446 & 0.573 & 0.570 \\
\hline
\end{tabular}

Table 5. Comparison of antimicrobial effects of root canal medicaments groups on clinically isolated E. faecalis strains in relation to standard E. faecalis ATCC 29212 on blood agar

\begin{tabular}{|c|c|c|c|c|}
\hline \multirow{2}{*}{$\begin{array}{c}\text { Root canal } \\
\text { medicaments groups }\end{array}$} & \multicolumn{2}{|c|}{$\begin{array}{c}\text { Antimicrobial effects } \\
\text { after 24 hours incubation }\end{array}$} & \multicolumn{2}{|c|}{$\begin{array}{c}\text { Antimicrobial effects after } 48 \\
\text { hours incubation }\end{array}$} \\
\cline { 2 - 5 } & t value & P value & t value & P value \\
\hline Chlorhexidine & 0.873 & 0.387 & 0.873 & 0.387 \\
\hline Diclofenac & 2.333 & $0.024^{*}$ & 2.333 & $0.024^{*}$ \\
\hline Diapex & 2.214 & $0.032^{*}$ & 2.214 & $0.032^{*}$ \\
\hline Amoxicillin & 7.722 & $0.000^{*}$ & 7.722 & $0.000^{*}$ \\
\hline Doxycycline & 1.100 & 0.277 & 1.100 & 0.277 \\
\hline
\end{tabular}

Figure 1. Zone of growth inhibition of E. faecalis on Muller Hinton (left) and blood agar plates (right) by the tested intracanal medicaments.

\section{Amoxicillin 2. Diclofenac 3. Chlorhixidine 4. Diapex 5. Doxycycline}

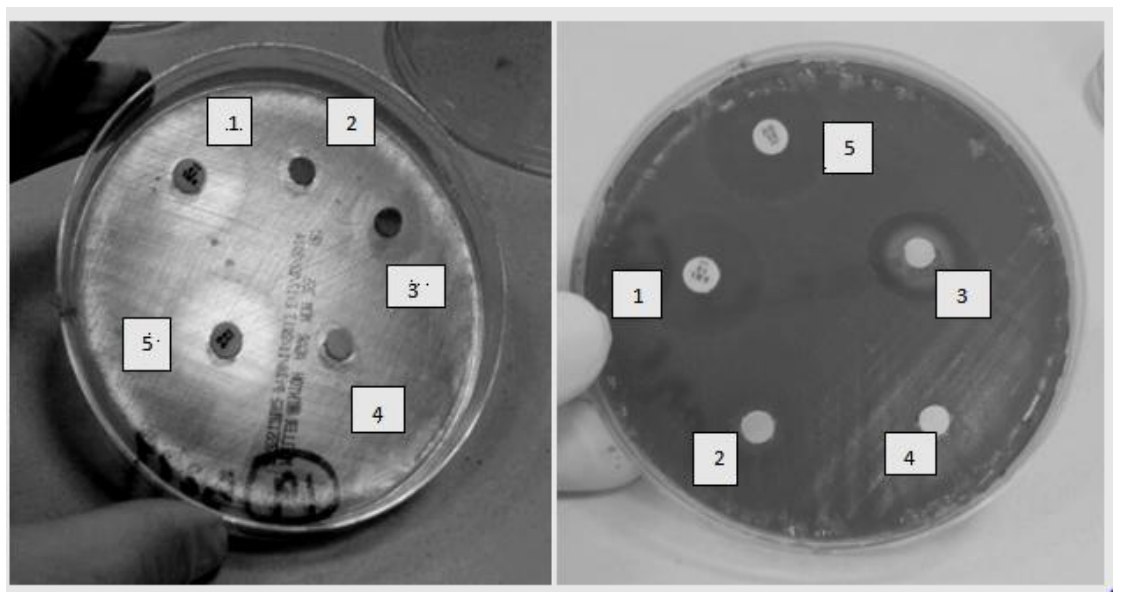

This observation was previously explained by the suggestion of McDonnell and Russell [28] and Puig Silla et al. [29]. who reported that Chlorhexidine is a positively-charged molecule that binds to the negatively-charged sites on the bacterial cell wall; leading to destabilization of the cell wall and interference with osmosis. The bacterial uptake of the chlorhexidine is very rapid, typically working within 20 seconds. Once the cell wall is damaged, chlorhexidine then crosses into the cell itself and attacks the cytoplas- mic membrane allows for leakage of components leading to cell death. In high concentrations, chlorhexidine causes the cytoplasm to solidify. Sassone et al [30] added that CHX has a good diffusing ability through the agar media.

In addition to direct bactericidal activity by disintegrating membranes, chlorhexidine may induce reactive oxygen species production in the alkaline environment. The production of these reactive species may inhibit E. faecalis growth by destruction of the cell 
wall and the plasma membrane mediated by nitric oxide Nishikawa et al, [31] . Moreover, CHX can inactivate lipoteichoic acid of this organism leading to the alleviation of inflammatory responses induced by E. faecalis and its lipoteichoic acid. [32]

The antibiotics tested in the present study showed that $68 \%$ of the tested strains were sensitive to doxycycline and $44 \%$ of them were senstive to amoxicillin .

Regarding to doxycyline, the results are in accordance with those of Skucaite et al [33] who found that $70 \%$ of the tested E. faecalis strains were sensitive to tetracycline and in partial agreement to that of Pinheiro et al [17] who found that higher percentage of $85.7 \%$ of their tested E. faecalis isolates were susceptible to doxycycline. On the other hand, these results do not coincide with that of Rams et al [34] who reported that $53.2 \%$ of the periodontal E.faecalis was resistant to tetracyclines. Coinciding with results of the present study, Sandya Kini et al., [35] concluded that doxycycline is the second effective antimicrobial agent after $\mathrm{CHX}$. Moreover, Khademi et al., [36] reported that both CHX and doxycycline had antibacterial activity against E. faecalis although the substantivity of CHX was significantly greater than doxycycline.

Yagiela et al [37] explained the mechanism of action of doxycycline $a$ it is primarily bacteriostatic, inhibits bacterial protein synthesis by binding to and interfering with ribosomes. This bacteriostatic action may be advantageous because in the absence of bacterial cell lysis, antigenic by- products such as endotoxin are not released [38]. Furthermore, Rizvi et al [39] attributed the higher efficiency of endodontic irrigate MTAD (composed mainly of tetracycline and citric acid) against E. faecalis, to the presence of doxycycline which may allow a prolonged antibacterial effect beside its low $\mathrm{pH}$, anti-collagenous activity, its capability of binding to dentinal tissues and its gradual release.

Regarding to amoxicillin, both Pinheiro et al [17] and Skucaite et al [33] studies on E. faecalis strains found that $100 \%$ of their strains were sensitive to it. Pinheiro et al [17] explained the lack of enterococcal resistance to penicillins in their study by the limited number of strains investigated and/or geographical differences. They also added that besides differences in geographical areas and origins of infections, changes in resistance pattern of bacteria may occur over time. Another contributing factor is that their strains were negative for $\beta$-lactamase production, which is the major mechanism of resistance for Amoxicillin, while strains in the present study were not tested for this factor.

On testing the antimicrobial efficiency of diclofenac none of the tested strains including the standard in the present study were sensitive to it. These results are in accordance with that of Johnston et al, [40] who showed that diclofenac conferred no antimicrobial activity on their tested strains. In contrast Salem-Milani et al [14] concluded that Diclofenac had distinct antibacterial activity against $E$. faecalis but the exact mechanism of this activity is unclear. However, they reported that previous studies have proposed inhibition of bacterial DNA synthesis or impairment of membrane activity.

In the present study diapex (calcium hydroxide with idoform in silicon oil) had no antibacterial action against E. faecalis. This agrees with previous studies that found calcium hydroxide to be ineffective against E. faecalis $[41,42])$ and confirms the results of
Sabrah et al [43] who found that calcium hydroxide was not inhibitory in the MIC and MBC assays against E. faecalis at any dilution, suggesting poor antimicrobial activity of this medicament.

Regarding to diapex, although iodoform is incorporated to improve the antibacterial properties of the material [9], it was observed that oil paste containing calcium hydroxide was largely lacking in both ion release and antimicrobial properties [44]. Moreover, Evans et al [45] demonstrated that the proton pump activity of E. faecalis offers resistance to high $\mathrm{pH}$ of calcium hydroxide.

Jhamb et al [46] added that when performing agar diffusion test, calcium hydroxide could not diffuse through agar plates very well or resistance could be a result of buffering agents in the culture medium. As the antibacterial effect of calcium hydroxide is mainly obtained from its high alkalinity, in the presence of buffering agents, the $\mathrm{pH}$ level may not be sufficient to give antibacterial activity.

The present study was done on Muller Hinton and blood agar media and the tested strains were examined after incubation for 24 and 48 hours to ensure validity of the results where non significant differences between them were recorded.

\section{In Conclusion}

- Within the limitations of this in vitro study, the data presented in this work showed that chlorhexidine is the most effective agent against E. faecalis.

- Although doxycycline and Amoxicillin were shown to be effective in eradicating E. faecalis, the development of antibiotic resistance should be considered when there is a proposal to use them to eradicate endodontic infections.

- Addition of iodoform with silicone oil to calcium hydroxide in diapex made calcium hydroxide as non effective agent against $E$. faecalis.

- Diclofenac may help in treatment of endodontic infection to relief pain but it is non effective as antimicrobial agent.

- However it must be considered that the antibacterial effectiveness of antimicrobials in vitro may be quite different when compared to mixed cultures present in a dynamic biological system, as usually occurs in vivo. Thus, the antimicrobial efficacy of the tested intracanal medicaments on bacterial biofilm still needs to be confirmed.

\section{References}

[1]. Siqueira JF Jr, Rôças IN, Favieri A, Lima KC (2000) Chemomechanical reduction of the bacterial population in the root canal after instrumentation and irrigation with $1 \%, 2.5 \%$, and $5.25 \%$ sodium hypochlorite. J Endod 26: 331-4.

[2]. Aravind, Gopikrishna V, Kandaswamy D, Jeyavel RK (2006) Comparative evaluation of the antimicrobial efficacy of five endodontic root canal sealers against Enterococcus faecalis and Candida albicans. J Conserv Dent 9:2-12.

[3]. Bailón-Sánchez ME, Baca P, Ruiz-Linares M, Ferrer-Luque CM (2014) Antibacterial and Anti-biofilm Activity of $\mathrm{AH}$ Plus with Chlorhexidine and Cetrimide. J Endod 40(7):977-81

[4]. Arias-Moliz MT, Baca P, Ordóńez-Becerra S, González-Rodríguez MP, Ferrer-Luque CM (2012) Eradication of enterococci biofilms by lactic acid 
alone and combined with chlorhexidine and cetrimide. Med Oral Patol Oral Cir Bucal 1;17(5):e902-6.

[5]. Tong Z, Ling J, Lin Z, Li X, Mu Y (2013) The effect of MTADN on 10 Enterococcus faecalis isolates and biofilm: an in vitro study. J Endod 39(5):674-8

[6]. Stuart CH, Schwartz SA, Beeson TJ, Owatz CB (2006) Enterococcus faecalis: its role in root canal treatment failure and current concepts in retreatment. J Endod 32(2):93-8.

[7]. Estrela C, Ribeiro RG, Estrela CRA, Pécora JD, Sousa-Neto MD (2003) Antimicrobial effect of $2 \%$ sodium hypochlorite and $2 \%$ chlorhexidine tested by different methods. Braz Dent J 14:58-62.

[8]. Estrela C, Silva JA, Alencar AHG, Leles CR, Decurcio DA (2008) Efficacy of sodium hypochlorite and chlorhexidine against Enterococcus faecalis - a systematic review. J Appl Oral Sci 16:364-368.

[9]. Gautam, S, Rajkumar B, Landge SP, Dubey, S ,Nehete P, et al (2011) Antimicrobial efficacy of Metapex (Calcium hydroxide with Iodoform formulation) at different concentrations against selected microorganisms-An in vitro study. Nepal Med Coll J 13(4): 297-300.

[10]. Estrela C, Bammann LL, Pimenta FC, Pécora JD (2001) Control of microorganism in vitro by calcium hydroxide pastes. Endod J 34: 341-5.

[11]. Estrela C, Estrela CRDA, Hollanda ACB, Decurcio DDA (2006) Influence of iodoform of antimicrobial potential of calcium hydroxide. J Appl Oral Sci 14: 33-37.

[12]. Gomes BP, Vianna ME, Zaia AA, Almeida JF, Souza-Filho FJ, et al (2013) Chlorhexidine in endodontics. Braz Dent J 24(2):89-102.

[13]. Dutta NK1, Annadurai S, Mazumdar K, Dastidar SG, Kristiansen JE, et al (2007) Potential management of resistant microbial infections with a novel non-antibiotic: the anti-inflammatory drug diclofenac sodium. Int J Antimicrob Agents 30:242-249.

[14]. Salem-Milani A, Balaei-Gajan E, Rahimi S, Moosavi Z, Abdollahi A, et al., (2013) Antibacterial Effect of Diclofenac Sodium on Enterococcus faecalis. J Dent (Tehran) 10(1):16-22

[15]. Mohammadi Z, Abbott PV (2009a) On the local applications of antibiotics and antibiotic-based agents in endodontics and dental traumatology. Int Endod J 42(7):555-67

[16]. Mittal N, Jain J (2013) Antibiotics as an intracanal medicament in endodontics: Areview. Indian Journal of Dentistry 4(1): 29-34

[17]. Pinheiro ET, Gomes BP, Drucker DB, Zaia AA, Ferraz CC, et al., (2004) Antimicrobial susceptibility of Enterococcus faecalis isolated from canals of root filled teeth with periapical lesions. Int Endod J 37(11):756-63.

[18]. Mohammadi Z, Abbott PV (2009b) Antimicrobial substantivity of root canal irrigants and medicaments: a review. Aust Endod J 35:131-9.

[19]. Rajkumar B, Dubey S, Dhole TN, Boruah LC, Gupta V (2012) Comparative efficacy of antimicrobial agents used in endodontic treatment on selected microorganisms. IJRD (1):30-35.

[20]. Clinical and Laboratory Standards Institute CLSI (2014) Performance Standards for Antimicrobial Susceptibility Testing; Twenty-Fourth Informational Supplement. 34(1):77-78.

[21]. Vianna ME, Gomes BP (2009) Efficacy of sodium hypochlorite combined with chlorhexidine against Enterococcus faecalis in vitro. Oral Surg Oral Med Oral Pathol Oral Radiol Endod 107(4):585-9.

[22]. Rocas IN, Siqueira JF, Santos KRN (2004) Association of Enterococcus faecalis with different forms of periradicular diseases. J Endod 30:315-20.

[23]. Chopra I (2013) The 2012 Garrod Lecture: Discovery of antibacterial drugs in the 21st century. J Antimicrob Chemother 68: 496-505.

[24]. Zerella JA, Fouad AF, Spańgberg LS (2005) Effectiveness of a calcium hydroxide and chlorhexidine digluconate mixture as disinfectant during retreatment of failed endodontic cases. Oral Surg Oral Med Oral Pathol Oral Radiol Endod 100: 756-761.

[25]. Mohammadi Z, Khademi AA, Davari AR (2008) Evaluation of the antibacterial substantivity of three concentrations of chlorhexidine in bovine root dentine. Iran Endod J 2:113-125.

[26]. Kandaswamy D, Venkateshbabu N, Gogulnath D, Kindo AJ (2010) Dentinal tubule disinfection with $2 \%$ chlorhexidine gel, propolis, morinda citrifolia juice, $2 \%$ povidone iodine, and calcium hydroxide. Int Endod J 43: 419-423
[27]. Lucena JMVM, Decker E M, Walter C, Boeira1 LS, Löst C, et al (2013) Antimicrobial effectiveness of intracanal medicaments on Enterococcus faecalis: chlorhexidine versus octenidine Int Endod J 46: 53- 61.

[28]. McDonnell G, Russell AD (1999) "Antiseptics and Disinfectants: Activity, Action and Resistance." Clinical Microbiology Reviews 12 ,1: 147-79.

[29]. Puig Silla M, Montiel Company JM, Almerich Silla JM (2008) Use of chlorhexidine varnishes in preventing and treating periodontal disease: a review of the literature. Med Oral Patol Oral Cir Bucal 13:E257-60.

[30]. Sassone LM, Fidel RA, Murad CF, Fidel SR, Hirata RJr (2008) Antimicrobial activity of sodium hypochlorite and chlorhexidine by two different tests. Aust Endod J 34(1):19-24.

[31]. Nishikawa T, Sato E, Choudhury T (2009) Effect of nitric oxide on the oxygen metabolism and growth of E. faecalis. J Clin Biochem Nutr 44:178-184

[32]. Lee JK, Baik JE, Yun CH, Lee K, Han SH, et al (2009) Chlorhexidine Gluconate Attenuates the Ability of Lipoteichoic Acid from Enterococcus faecalis to Stimulate Toll-like Receptor 2. J Endod 35(2):212-5.

[33]. Skucaite N, Peciuliene V, Vitkauskiene A, Machiulskiene V (2010) Susceptibility of endodontic pathogens to antibiotics in patients with symptomatic apical periodontitis. J Endod Oct;36(10):1611-6.

[34]. Rams TE, Feik D, Mortensen JE, Degener JE, Winkelhof AJ (2013) Antibiotic Susceptibility of Periodontal Enterococcus faecalis. Journal of Periodontology 84 (7):1026-1033.

[35]. Sandya Kini K, Kundabala M, Indira Bairy, Vasudev Ballal, Ramya Shenoy (2011) In vitro evaluation of the antimicrobial efficacy of 5\% Doxycycline, $0.2 \%$ Chlorhexidine gluconate and $2.5 \%$ Sodium hypochlorite used alone or in combinations against Enterococcus faecalis; Endodontology (2):30-36.

[36]. Khademi AA, Saleh M, Khabiri M, Jahadi S (2014) Stability of antibacterial activity of Chlorhexidine and Doxycycline in bovine root dentine. J Res Pharm Pract 3(1): 19-22.

[37]. Yagiela JA, Dowd FJ, Neidle EA (2004) Pharmacology and therapeutics for dentistry. Antibacterial and antibiotic dugs. 5th(edtn). St. Louis: Mosby Elsevier. 619-59.

[38]. Torabinejad M, Khademi AA, Babagoli J, Cho Y, JohnsonWB, et al (2003) A new solution for the removal of the smear layer. J Endod 29(3):170-5.

[39]. Rizvi A, Zafar MS, Farid WM, Gazal G (2014) Assessment of Antimicrobial Efficacy of MTAD, Sodium Hypochlorite, EDTA and Chlorhexidine for Endodontic Applications: An In vitro Study ; Middle-East Journal of Scientific Research 21 (2): 353-357.

[40]. Johnston D, Choonara YE, Kumar P, du Toit LC, van Vuuren S, et al (2013) Prolonged delivery of ciprofloxacin and diclofenac sodium from a polymeric fibre device for the treatment of periodontal disease. Biomed Res Int.;2013:460936

[41]. Distel JW, Hatton JF, Gillespie MJ (2002) Biofilm formation in medicated root canals. J Endod 28:689-93

[42]. de Souza CA, Teles RP, Souto R, Chaves MA, Colombo AP (2005) Endodontic therapy associated with calcium hydroxide as an intracanal dressing: microbiologic evaluation by the checkerboard DNA-DNA hybridization technique. J Endod 31:79-83.

[43]. Sabrah AH1, Yassen GH, Gregory RL (2013) Effectiveness of antibiotic medicaments against biofilm formation of Enterococcus faecalis and Porphyromonas gingivalis. J Endod 39(11):1385-9.

[44]. Fulzele P, Baliga S, Thosar N, Pradhan D (2011) Evaluation of calcium ion, hydroxyl ion release and $\mathrm{pH}$ levels in various calcium hydroxide based intracanal medicaments: an in vitro study. Contemporary Clinical Dentistry 2 (4), 291-5

[45]. Evans M, Davies JK, Sundquist G, Figdor D (2002) Mechanisms involved in the resistance of Enterococcus faecalis to calcium hydroxide. Int Endod J 35:221-8.

[46]. Jhamb S, Nikhil V, Singh V (2010) An in vitro study of antibacterial effect of calcium hydroxide and chlorhexidine on Enterococcus faecalis. Indian J Dent Res 21(4):512-4. 